\title{
Transport policy optimization with autonomous vehicles
}

\section{Journal Article}

Author(s):

Bösch, Patrick M.; Ciari, Francesco; Axhausen, Kay W. (D)

Publication date:

2018-12-01

Permanent link:

https://doi.org/10.3929/ethz-b-000238539

Rights / license:

In Copyright - Non-Commercial Use Permitted

Originally published in:

Transportation Research Record 2672(8), https://doi.org/10.1177/0361198118791391 
1 Transport Policy Optimization with AVs

2 Date of submission: 2017-11-15

3

Patrick M. Bösch, Corresponding Author

IVT, ETH Zürich,

CH-8093 Zürich

phone: +41-44-633 3952

4 email: patrick.boesch@ivt.baug.ethz.ch

Francesco Ciari

LIFE, Joanneum Research,

A-8020 Graz

phone: +43-316-876 7670

email: francesco.ciari@joanneum.at

Kay W. Axhausen

IVT, ETH Zürich,

CH-8093 Zürich

phone: +41-44-633 3943

email: axhausen@ivt.baug.ethz.ch

6 Words: 6404 words +2 figures +2 tables $=7404$ word equivalents 


\begin{abstract}
Autonomous vehicles (AVs, here self-driving and driverless vehicles, SAE (1) levels 4 and 5) are becoming more clearly a reality. Potential services based on AVs, their detailed design for high performance, and their consequences for the transport system are of increasing importance. This paper investigates policy combinations for a world with such services. The policy measures investigated are pricing of public transport (through subsidies), pricing of private motorized transport (through taxation or mobility pricing), and the organization of AV services (monopoly vs. oligopoly, with or without ride-sharing). Further, the perception of travel times for autonomous private cars is considered.

All combinations of policies (respectively two to four levels each) are implemented in a simulation to determine their synergies. The applied model is the agent-based transportation simulation MATSim. The scenario employed for the tests is the agglomeration of Zug, Switzerland.

The results suggest that, given the current spatial distribution of the demand and the current transport system, AV systems are only able to reduce travel times at the cost of substantial mode shifts and additional vehicle kilometers driven. Of the tested policy measures, although all showed the expected causality, only the organizational form of the AV service had a statistically significant effect.

8 Therefore, this paper suggests that policy makers are critical when assessing the promises of 9 future transport services. To invest the benefits of automation into an improvement of the 2o existing transport system might be a good alternative.
\end{abstract}




\section{INTRODUCTION}

Autonomous vehicles (AV), in this paper driverless and self-driving vehicles (SAE (1) level 4 and 5), promise to revolutionize the transport system. The possibility of driverless relocations in shared vehicle systems, a substantial cost reduction in public transport operations (2), and driving transformed into productive time are just a few of the revolutionary features expected from AVs (for a comprehensive overview see (3)).

Such fundamental changes of the transport system were topics of early papers on AVs (e.g. $(3-5)$ ). Recently however, the focus shifted to more detailed questions. While insight on the required fleet sizes to serve a city $(6-10)$, or the organization of new services (11-14) is background knowledge on the possibilities offered by AVs, they are years, maybe decades away from implementation.

Thanks to this background knowledge however, it is now possible to return to the fundamental question of transport system organization: Given all these new opportunities, but also given the current system as a starting point, and given financial and political constraints, how should the future transport system best be organized?

This paper aims to assess different possibilities AVs allow for future transport services given their benefits and costs for society. It evaluates policy measures available to policy makers to influence and shape the transport system, in order to make the most out of the benefits AVs could possibly bring.

Finding a preferred combination of policy measures is a classic optimization problem 15 17). A target function is evaluated in a multi-dimensional space of possible measures and their respective implementation ranges. It is evaluated in an appropriate model of the transport system, meaning that it has to be able to represent the system dynamics and responses to the proposed policy measures. At the same time, it should be fast enough to test many policy combinations. While an appropriate model is certainly most important, another fundamental part is the definition of the possible policies (15). Policy makers have the following possibilities to influence the transport system: Through direct management they can optimize the usage of existing infrastructure (e.g. traffic management), or, assumed sufficient financial means, they can provide new or extend infrastructures and/or public transport services. Using taxes (incl. mobility pricing) and subsidies, they can change the costs of certain modes versus others and of the transport system overall, and using legislation, they can regulate the organization and usage of the transport system (e.g. speed limits, priority lanes, etc.). And finally yet importantly, using advertising campaigns, they can (try to) influence general attitudes towards different modes.

The third element is the definition of the target function. The goal of any transport system should be to move people and goods fast, cheap, easy, safe, and sustainable. An optimal transport system maximizes all these targets at the same time. However, as long as safe and cheap beaming is not possible, trade-offs need to be assessed and priorities need to be set. While endless variations in target weighting exist and any choice can be debated, the list of goals per se is manageable and indicators can be found (18).

In summary, as literature shows (1517), combining the available possibilities to influence the system with a comprehensive target function and an appropriate transport model effectively allows identifying high-performing transport policy strategies.

While the above is an established methodology, attempts applying it to investigate how a socially beneficial AV based transport system could and should look like are very limited so far. Literature is so far mostly restricted to either describing the system qualitatively or focuses on detailed, mostly operational questions. 
This study is an attempt to fill this gap. Starting from the current system and considering financial and legislative constraints, this paper focuses on policies to influence the price of existing transport services and the organization of future, AV-based transport services. Given the importance of the value of travel time in $\mathrm{AVs}$, but also its uncertainty, these policies are tested against three assumed perceived travel times in AVs.

This set is evaluated against two performance indicators (instead of a single target function). These are the total travel time of all trips in the area, representing the "output" of the transport system, and total vehicle kilometers traveled (VKT) representing the costs required and externalities produced.

The methodology is applied to the region of Zug, Switzerland. The region is modeled with an agent-based transport model (MATSim, (19)), which, given its ability to represent single individuals (agents), is particularly suitable to investigate the impact of policy measures. In fact, the impact at the systemic level is the consequence of individual reactions to the policies.

In this paper, the next section describes the methodology, the chosen policy measures and objectives in more detail. The section Transport Model introduces MATSim and describes the Zug model. Next, specific sections present, and discuss the results. The section Conclusion presents policy recommendations based on the results and concludes the paper.

\section{METHODOLOGY}

The methodology followed was proposed by May et al. (15) for the development of optimal integrated transport policy strategies. They applied it to different European cities to evaluate combinations of transport policies. Here, given that it is unknown when AVs will be available and to account for the many other uncertainties on the future transport system, a simplified version of the original methodology is used. The temporal aspects of the policy measure staging are neglected and the policies are less detailed.

The methodology consists of three parts:

First, development of possible policy measures including a respective range for each policy.

Second, definition of an appropriate objective function that evaluates how well different combinations work.

Third, their application in a model of the transport system.

With an analysis of the full policy ranges, not only the preferred strategy can be identified, but also the transport system's sensitivity to the different individual policy measures can be evaluated. The model used is a MATSim scenario of the Swiss area of Zug. An introduction to MATSim and a description of the scenario follows in the next section.

\section{6olicy Measures}

7 The selection of policy measures depends not only on the system characteristics, but also on 38 external restrictions. On top of the obvious ones, such as physical feasibility and financial 9 restrictions, the required political support is also a major condition, if not the most important one. The policy measures proposed here were designed and selected with this in mind.

As mentioned earlier, the number of possible ways for policy makers to influence the transport 42 system are limited. Investments in services or infrastructure, influencing price through taxes (incl. ${ }_{43}$ mobility pricing) or subsidies, legislative measures, direct traffic management, and advertisement 44 campaigns are the main ones. The policies investigated are selected from this set. Most policy 45 measures allow for a continuous or near-continuous range in their application. For simplicity 
however, only discrete levels were investigated here.

\section{Policy Measures for Existing Modes}

Existing modes include mass transit public transport (PT), the slow modes (SM) walk and bike, and motorized individual transport (MIT). For PT and MIT, the respective autonomous version is assumed (aPT and aMIT).

The two policy measures aPT pricing and aMIT pricing were selected. Other possible measures are not further investigated either for their political and/or financial feasibilities (e.g. infrastructure projects), or for their impact being difficult to quantify (e.g. advertisement campaigns). A closer investigation of other possible measures is part of future work.

These two are complemented by different assumptions on the possible comfort changes through automation.

- Pricing of aPT represents any policy measures increasing or decreasing the user price of aPT. The main policy lever is the level of subsidies. The automation of aPT (busses) was estimated to half its production cost (2). As today subsidies cover $50 \%$ of the cost of Swiss PT (20), the following three levels of aPT subsidies are investigated: No subsidies, which results in the same price for aPT as for PT today $(0.27 \mathrm{CHF} / \mathrm{km}(2))$; the same relative level of subsidies (50\%) as today, which results in half the price for aPT as for PT today $(0.13 \mathrm{CHF} / \mathrm{km})$; and the same absolute level of subsidies as today, which results in a free at the point of use aPT.

- Pricing of aMIT aims at increasing or decreasing the average cost per distance for aMIT. The main policy instruments to achieve this are taxes (e.g. on fuel or vehicles) or mobility pricing (for areas or road categories). Bösch et al. (2) found the cost of aMIV to be similar to today's MIV costs. Therefore, two possibilities were assumed here: first, a similar level of taxes and/or mobility pricing as today which results in the same marginal cost of aMIV as MIV today (0.18 CHF/km (2)); and second, new taxes or mobility pricing for aMIV in the range of $25 \%$ of today's cost of MIV, resulting in $0.22 \mathrm{CHF} / \mathrm{km}$.

- Comfort changes of aMIT is not actually a policy measure, but represents the expected benefit of autonomous driving technology to transform driving into productive time. It thus reduces the negative value of travel time (VOT) in aMIT. Three levels are investigated here: The same VOT as today, that is as if driving $(23.29 \mathrm{CHF} / \mathrm{h}(21))$; the same VOT for aMIT as for PT (14.43 CHF/h (21)); and, given that other passengers represent for most people a negative factor of traveling with PT (22), a 25\% lower negative VOT for the individual aMIT as for PT, resulting in $10.82 \mathrm{CHF} / \mathrm{h}$.

\section{Organizational Form of Future Modes}

Future modes represented here are all based on autonomous taxis, which can be operated as a traditional taxi service (aTaxi) or as a ride-sharing service (aRS). They can be operated by a public agency or by a private company, which can provide different comfort and price levels. Other models and forms of future modes, such as for example autonomous mini-buses, point-topoint shuttles, etc. are neglected here.

The future form of organization of such services is an important question policy makers should start to think about. If they will wait too long before taking action, the market will organize itself. This might result in a suboptimal system from a societal point of view.

To represent these different forms of organization, the following services are proposed as "policy measures": a monopoly aTaxi service, a monopoly aRS service, and an oligopoly in which six 
different services compete ( 3 aTaxi and 3 aRS).

Following the above assumptions, negative VOT is assumed to be the same for aRS as for PT, while for aTaxis it is assumed $25 \%$ less negative (more comfortable). The monetary prices per passenger kilometer (PPKM) for the services follow (2). The fleet sizes for the services were estimated based on (10). They found that for a good level of service, one aTaxi could replace four private cars. Here, the monopolist's fleet was expected to serve $25 \%$ of the population with such a level of service. Therefore, $25 \%$ of $25 \%$ of the current car fleet of Zug (96'000 (23)) results in 6’000 aTaxis. For aRS, a 33.3\% smaller fleet was assumed (4'000 vehicles). In the competitive situation, each of the services is assumed to have a fleet of one third of the respective monopolist (rounded up to the next 500 vehicles). This results in total 6'000 aTaxis and 4'500 aRS AVs in the area, which increases to total fleet by $75 \%$ resp. $162.5 \%$ compared to the monopolistic cases. This is realistic, as each service requires a substantial fleet to offer a good service in the area.

This results in the following four cases:

1. A monopoly service offering 6'000 aTaxis for individual transport (VOT: $10.82 \mathrm{CHF} / \mathrm{h}$, PPKM: $0.46 \mathrm{CHF} / \mathrm{km}$ ).

2. A monopoly service offering 4'000 AVs for ride-sharing (VOT: $14.43 \mathrm{CHF} / \mathrm{h}, \mathrm{PPKM}$ : $0.30 \mathrm{CHF} / \mathrm{km})$.

3. An oligopoly of services, represented here by six services, three different experiences (VOT as above, $-25 \%$, and $+25 \%$ ) and matching prices (price as above, $+25 \%$, and $-25 \%$ ) and each with aRS (1'500 vehicles per service) or as aTaxis (2'000 vehicles per service).

4. No AV-based service (base case).

This results in $(3 \times 2 \times 3 \times 4=) 72$ different transport scenarios. The policy measures and their ranges, as well as the assumed levels of comfort of aMIT are summarized in Table 1 .

TABLE 1 Overview of the policy measures investigated in this paper.

\begin{tabular}{lllll}
\hline Policy measure & Level 0 & Level 1 & Level 2 & Level 3 \\
\hline Pricing of aPT & No change & $-50 \%$ & $-100 \%$ & - \\
Pricing of aMIT & No change & $+25 \%$ & - & - \\
Comfort changes of aMIT & No change & as PT & as PT - 25\% & - \\
Future modes & None & Monopoly & Monopoly & Oligopoly \\
& & aTaxi & aRS & (6 services: \\
& & & 3 comfort-price levels, \\
& & & aTaxi / aRS $)$ \\
\hline
\end{tabular}

\section{Performance Indicators}

Instead of a single objective function, two performance indicators are used. The first, total travel time (TT), represents the performance of the system in providing access to activities. The second, total vehicle kilometers traveled (VKT), represents monetary costs and externalities of the transport system (18). While more detailed analysis is required for the assessment of individual solutions, the reduction to these two indicators allows comparing the solutions without politically influenced weights (as it would be the case for single target function values). 
Total VKT are often used in transport studies as the direct and single indicator to calculate various costs of the system. Examples range from the pure monetary cost (fuel and vehicle cost per VKT), health cost (accidents per VKT), negative externalities (noise per VKT), to ecologic costs (e.g. CO2 per VKT) (18). Here, for each case, the total VKT are provided directly as a proxy for the overall cost of the transport system. They are calculated as the sum of VKT of all modes.

The total TT of all trips in the analysis area represents the transport system's performance in providing access to activities. It serves as an illustrative and direct indicator for the performance as the number of trips and their origins and destinations remain constant across all scenarios.

For the monopolist scenarios, profitability represents a third factor. It is calculated by multiplying the total passenger kilometers of the AV service with the passenger price and comparing this to the cost per VKT multiplied with the total VKT of the service. Profitability indicates the requirement for subsidies under the proposed pricing scheme.

\section{TRANSPORT MODEL}

\section{MATSim}

The transport model used here is a MATSim model. MATSim, an agent-based transport model (19), is chosen for its suitability for the evaluation of transport policies targeting individuals and their traveling decisions and because of its computational performance.

MATSim uses a co-evolutionary, iterative optimization process to identify the user equilibrium of a transport system. A population of agents with daily plans, listing activities to be executed and routes and modes to get from one activity location to the next, represents transport demand. Each iteration, a random sample of agents can mutate their plans (change modes, routes, or departure times). Then, the transport simulation simulates a full day with all agents executing their daily plan. A queue model is used to simulate traffic (24). After the simulation, each agent scores his plan with a scoring function. It rewards activity time and punishes travel time and cost. During the iterative process, plans with good scores are kept, while plans with bad scores are discarded.

The MATSim functionality particularly important for this study, is the simulation of AVs (14, 25). In the basic configuration used here, it simulates AV-based taxi services organized by a central dispatcher. Agents, which would like to use a taxi, place a request at the central dispatcher, which looks for the closest free taxi and assigns it to the agent. The taxi serves the agent and waits at the agent's destination for the next assignment. Relocation is not included. The taxis are initially placed based on population density.

Additionally, it also allows for the simulation of ride-sharing (25). With ride-sharing, as long as the first passenger's additional travel time remains less than a given threshold (here 800 seconds), the dispatcher can pool another passenger.

\section{Region of Zug}

The city of Zug is a mid-size town located about halfway between Zurich and Lucerne. It has $29^{\prime} 000$ inhabitants and is the capital of the canton of $\mathrm{Zug}$ with 120'000 inhabitants (23). The canton approximately represents the agglomeration of Zug (26). 
From a simulation point of view, Zug is very suitable for this study as it is a large enough town to have its own agglomeration and its own public transport system (27) densely covering the main settlement area (Figure 1), but also small enough to allow for quick computation times even if the full population is represented by agents. This representation is required to get realistic results on the usage of public transport and taxi services (28).

Additionally, Zug attracts increasing attention for transport experiments in Switzerland. It was selected for an AV shuttle experiment by the Federal Swiss Railways (29). Starting summer 2017, an AV shuttle will connect Zug main train station with a nearby research campus. Recently, the canton of Zug was also selected by the Swiss Federal Government for a study on the potentials and the possible effects of mobility pricing $(30)$. A study on future transport systems and suitable transport policies for Zug is therefore a good fit with these events.

\section{MATSim Model of Zug}

The MATSim model of Zug used for this study is cut from a recently developed 2015 MATSim model for Switzerland (see (31) for a detailed description). The model covers all agents having their home within the area, that is the agglomeration of Zug (Figure 1), and all agents of the full Switzerland scenario which have an activity in the area or pass through the area. Within the area, the modeled infrastructure (street network, public transport, facilities) is fully detailed as described in (31). Outside of the area, the street network is modeled on the level of arterial roads (capacity min. 1'000 veh./h) and public transport is reduced to rail lines only. AV services are restricted to trips within the area and empty rides with private AVs are excluded.

The scenario represents the full population, which means that every agent in the simulation represents one real person (assuming no error in the available statistics). In 2015, the population of canton Zug consisted of 117'695 persons (23). To avoid border effects however, analysis of the simulations is focused on the densely populated main settlement area of Zug and its inhabitants only ((32), outlined in Figure 1 ).

In the baseline scenario, the trip-based modalsplit of these agents is $14 \%$ PT, $42 \%$ MIT, and $44 \%$ SM. Compared to the official statistics (14\% PT, 37\% MIT, 48\% SM, (33)), there is a slightly higher use of MIV at the expense of SM. This is balanced however, by the average distance traveled per agent per day with $8 \mathrm{~km} / \mathrm{d}$ PT, $21 \mathrm{~km} / \mathrm{d}$ MIT, and $3.1 \mathrm{~km} / \mathrm{d}$ SM compared to the official $7 \mathrm{~km} / \mathrm{d}$ PT, $26.6 \mathrm{~km} / \mathrm{d}$ MIT and $3.5 \mathrm{~km} / \mathrm{d} \mathrm{SM}(34)$. This leads to the conclusion that the model fits well and that the deviations are likely due to the different sampling processes. This is further supported by the reasonably fitting average speeds (Model: $17.3 \mathrm{~km} / \mathrm{h} \mathrm{PT}, 48.7 \mathrm{~km} / \mathrm{h} \mathrm{MIV}$, 2.6km/h SM; (34): 20.2km/h PT, 46.9km/h MIV, 5.9km/h SM).

\section{RESULTS}

In total 72 scenarios were simulated. Each simulation was run for 250 iterations. This is a low number of iterations for MATSim runs but considered sufficient for an indication of the system development. Nevertheless, results indicate that AV-based services might gain more mode share until user equilibrium. The following results should therefore be seen as conservative indications on the user potential of AV based services.

\section{Organizational Forms of Future Modes}

This subsection compares all scenarios. It focuses on the performance of the different organizational forms of the AV based services. For each scenario, Figure 2 presents the total TT of all 


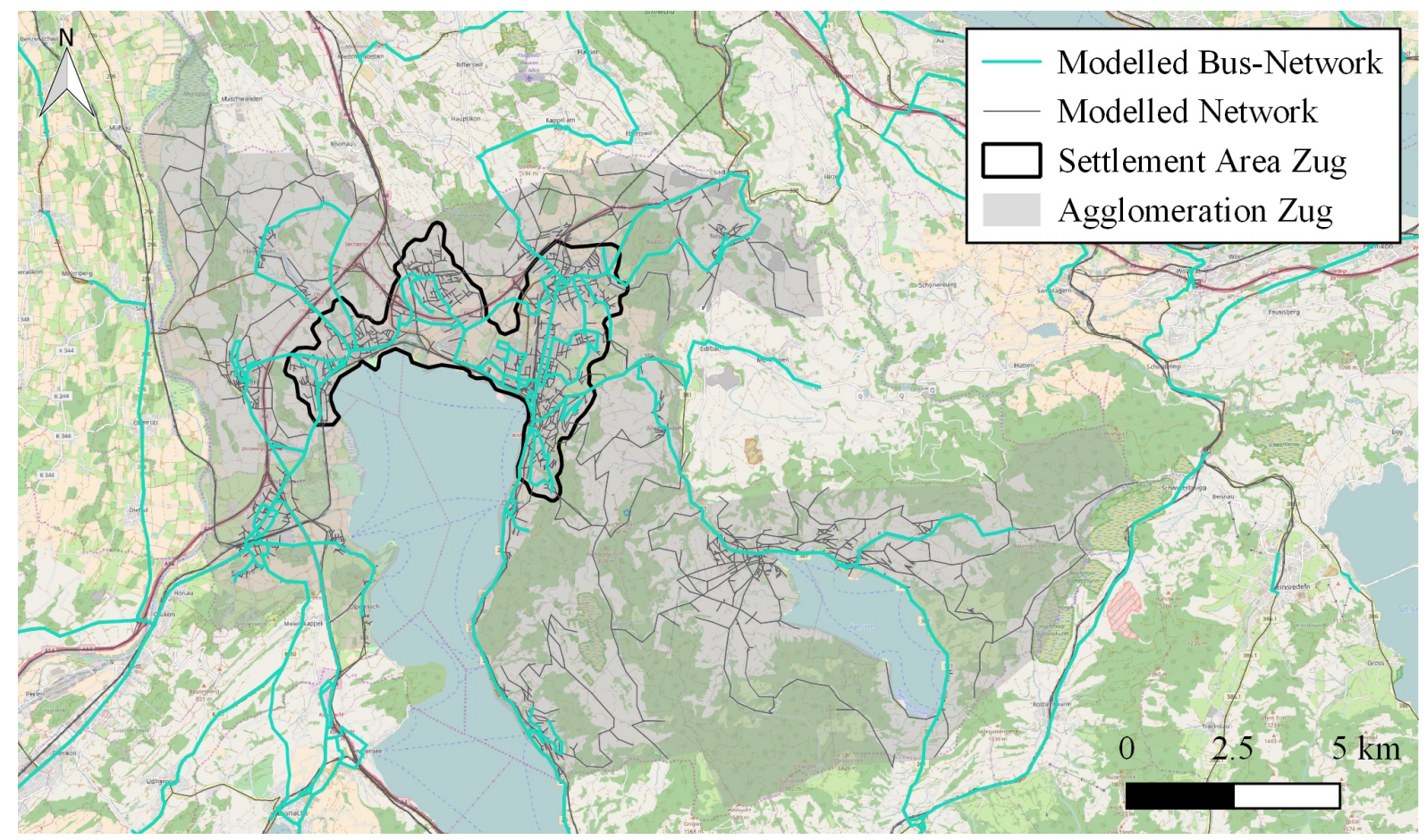

Source: Background from openstreetmap.org

\section{FIGURE 1 Zug area.}

agents versus the total VKT in the area, differentiating the scenarios based on the organizational form of the AV based service.

Figure 2 , especially Figure 2(b), shows that monopoly aTaxi services have the potential to reduce TT. But this improvement comes at a great cost: $4.1 \%$ reduction in TT for $16.0 \%$ increase in VKM (averages across all combinations without outliers). The other policy configurations show a similar increase in VKM, but they are not able to reduce the overall TT. With aTaxis, the expected pick-up and drive time are 2.6 minutes and 2.4 minutes, while for aRS these are 12.4 minutes and 10.9 minutes, despite similar served average Manhattan trip distances (aTaxi: $1.28 \mathrm{~km}$, aRS: $1.32 \mathrm{~km}$ ). The reason is that, in its current implementation, aRS gives always priority to bundling of trips vs. single trips, even if this means substantial detours. Oligopolies, consisting of both aTaxi and aRS services, lie in between the other two clusters.

The tight clustering of configurations shows that the chosen organizational model is the most important determinant for future performance of the system. Other policy measures (price of aMIT and aPT, VOT of aMIT) appear to have only a minor effect within the cluster.

Several AV scenarios produce substantially more TT than the rest of their service's cluster. These are considered outliers. Analysis showed that major traffic congestion was the reason for these outliers. No clear common reason could be identified however, which indicates that, independent of the chosen policy measures, the additional VKM are bringing the system generally closer to breakdown (major congestions) with occasional tipping.

\section{Effect of Policy Measures on Total Travel Time}

To analyze the effect of the different policy measures, Table 2 presents a multiple linear regression analysis of all scenarios except the outliers. The system performance, i.e. total TT, is the response variable of the model. The model shows that, as expected from Figure 2 ; indeed the influence of 


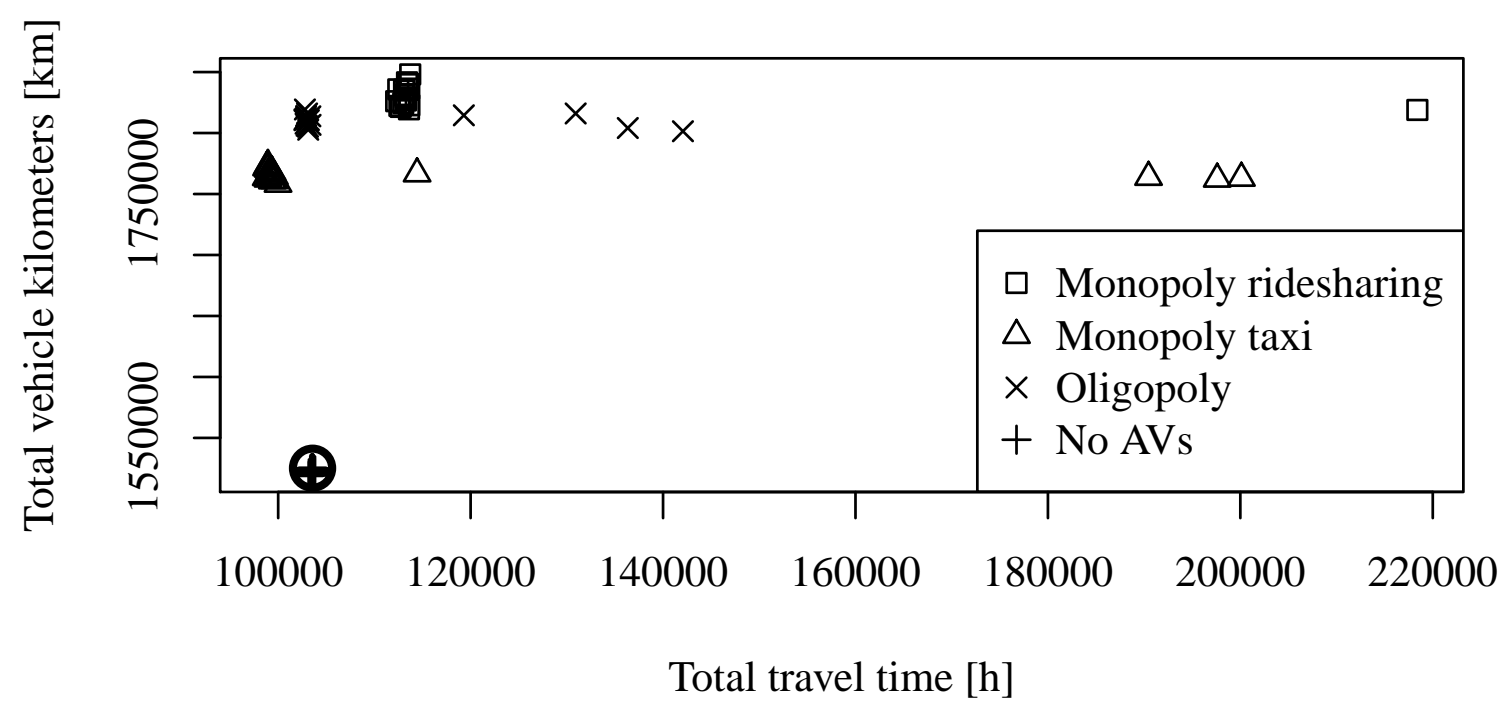

(a) Complete set of configurations.

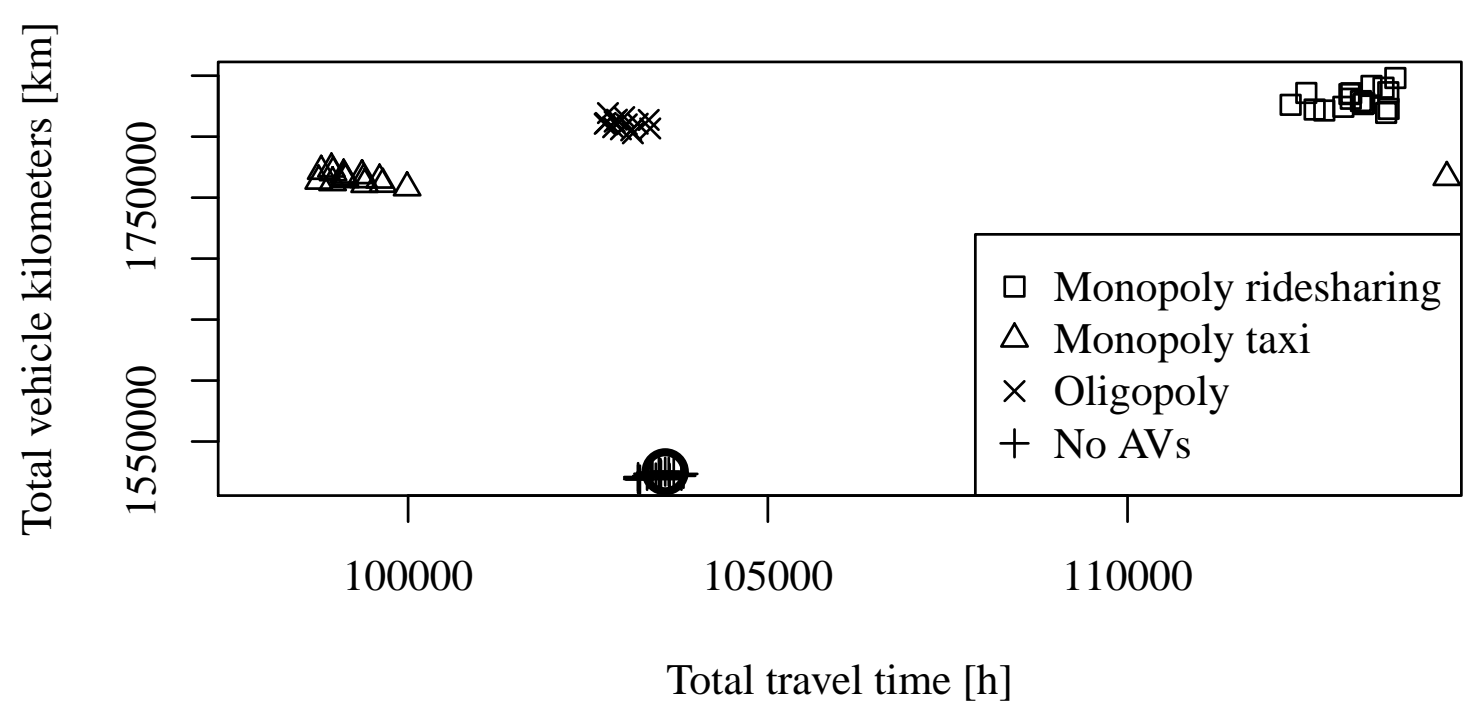

(b) Focus on main configuration clusters.

FIGURE 2 TT-VKT trade-off by market configuration (reference scenario, i.e. no AV service and no policy implemented, highlighted with a circle). 


\section{TABLE 2 Multiple linear regression analysis of total travel time with policy measures as variables (outliers excluded from analysis).}

\begin{tabular}{lrrrr}
\hline Coefficients & Estimate & Std. Error & $\mathrm{t}$ value & \\
\hline (Intercept) & 103665.31 & 373.51 & 277.54 & $* * *$ \\
Price of aPT & 85.11 & 97.24 & 0.87 & \\
Price of aMIT & -247.46 & 322.63 & -0.76 & \\
VOT of MIT - PT & 109.63 & 102.65 & 1.06 & \\
VOT of MIT - PT_plus & 64.68 & 98.64 & 0.65 & \\
AV organization - RS monopoly & 9672.90 & 107.73 & 89.79 & $* * *$ \\
AV organization - Taxi monopoly & -4276.57 & 114.02 & -37.50 & $* * *$ \\
AV organziation - Oligopoly & -492.51 & 113.87 & -4.32 & $* * *$ \\
\hline
\end{tabular}

Signif. codes: $0{ }^{\prime} * * *, 0.001^{\prime} * *, 0.00^{\prime} *{ }^{\prime} 0.05^{\prime},{ }^{\prime} 0.1^{\prime},{ }^{\prime} 1$

the organizational models is highly significant while the other measures have no statistically significant effect. This is surprising as the interventions are substantial. It seems that, at least within the degrees of freedom of the model (e.g. no activity location adaptation), neither a substantial price reduction of aPT $(-50 \%$ and $-100 \%)$ could significantly reduce the total TT, nor could a substantial increase in the price of aMIT $(+25 \%)$.

Concerning the observed relations, the model represents expected associations. A reduction of the price of aPT seems to lead to lower travel times (positive estimate), while a reduction of the price of aMIT increases total TT (negative estimate). Also, an increase in attractiveness of aMIT (i.e. decrease in VOT) leads to the expected decrease in total TT (positive estimate).

\section{Monopolist aTaxi Strategies}

Under the chosen pricing scheme and the provided fleet sizes, none of the aTaxi monopolists could operate profitable. Excluding the outliers from the analysis, the average passenger trip with an aTaxi was $1.84 \mathrm{~km}$ long. To serve this trip, the average pick-up distance (driving distance from the closest free aTaxi to the passenger) was $2.13 \mathrm{~km}$, leading to a productive to total VKT ratio $\left(=\frac{1.84 \mathrm{~km}}{1.84 \mathrm{~km}+2.13 \mathrm{~km}}\right)$ of $46 \%$.

Here, for a more detailed picture, the neutral aTaxi monopolist scenario is compared to the reference scenario. The neutral scenario is chosen to avoid random influences of other policy measures (see above). By multiplying the total travel time of each mode with its VOT, the TT improvement of the aTaxi scenario vs. the reference scenario can be monetarized. This approach results in perceived travel cost savings of CHF 185'000 per day. These savings could be obtained by accepting an increase of $15.7 \%$, i.e. $240^{\prime} 000 \mathrm{~km}$, in VKM per day. The modalsplit of the aTaxi scenario is $32.9 \%$ aTaxi, $35.5 \%$ car, $11.7 \%$ PT, and $19.9 \%$ slow modes. Compared to the reference scenario ( $47.9 \%$ car, $16.0 \%$ PT, and $36.0 \%$ slow modes), this means aTaxi gains substantially from all three traditional modes, but most from slow modes (16.1 percentage-points).

\section{DISCUSSION}

The results presented in this paper surprise in the sense that literature (e.g. (9, 11)) usually assumes - more or less explicitly - that shared AV fleets improve the transportation system. Here, comparing different possible systems with shared AVs and especially, comparing them with the 
case without such services, reveals that such an improvement depends heavily on the chosen implementation. Additionally, while positive effects of shared AV fleets can be expected, e.g. 12.4 percentage points of mode share switching from private cars to aTaxis which would result in a substantial fleet size reduction (10), they might also come with a great cost in additional VKM, and an increased risk for congestion as suggested by the presence of the outliers. The additional VKT originate from empty rides, but also from substantial mode share changes from the VKM-neutral modes aPT and SM to aTaxis (16.1 percentage points from SM and 4.3 from aPT).

The example of Uber in Manhattan (35) indicates that this is indeed a valid observation. There, additional empty miles by Uber taxis combined with attraction of former pedestrians or PT users, led to an increase of VKT in a system already operating at its limits and thus a worsening of the overall situation.

Another surprise from the results is that policy measures (pricing of aMIT and aPT and reduction of VOT of aMIT), while showing the expected relations, seem to have no statistically significant effect on the total TT - or at least a negligible one compared to the chosen implementation of AVs. This was certainly expected differently and will be subject of future work.

The same applies to the observation that aRS services reached substantial mode shares (in average 13\%) despite being very inefficient $(8.4 \mathrm{~km}$ of average driving distance for trips with an average Manhattan origin-destination distance of only $1.3 \mathrm{~km}$ ). While this indicates a remarkable attractiveness of these services, it also shows the importance of careful system and pricing scheme design. The latter further emphasized by the non-profitability of the aTaxi services.

This leads to the discussion of the transport model. Even though the transport model scenario reproduces the existing transport situation well, parameter choices and design of the offered AV based services indicate future work. The fleet sizes were estimated based on an educated guess. As required fleet sizes heavily depend on local context (e.g. car ownership rates, spatial structure, PT infrastructure), a more in depth analysis of the required fleet size will be part of future work. The same applies for the chosen level of prices. Although based on a detailed estimation (2), the assumptions leading to the estimated prices did not fully apply to the scenario at hand and are, together with the sub-optimal fleet sizes, a suspected reason for the non-profitability of the aTaxi services. The simulation of the AV fleets themselves is - up to now - also rather simple. Relocation to minimize pick-up distances and more complex assignment algorithms are in development and might be applied to future studies.

These limitations should be considered when interpreting the results. But nevertheless, the results represent valuable indications that the introduction of services based on shared AVs might come with considerable additional VKM and not always with an improvement of total TT. Having systematically reached this conclusion certainly adds to the present discussion on possible AV based services.

\section{CONCLUSION}

In this paper, different policy measures for future transport systems were investigated. They included different levels of subsidies for aPT, of pricing of aMIT, and different organizational frameworks (monopoly vs. oligopoly) for AV based services (Table 1). This was complemented with different assumptions on the future VOT of aMIT, which means how comfortable private AVs will be. 
Following (15), different possible combinations of these policies and assumptions were simulated in a scenario of the agglomeration of Zug, Switzerland, using MATSim (19). Zug is small enough to allow simulating the substantial number of scenarios, but large enough to produce relevant outcomes.

The results of these simulations showed that scenarios including AV services, independent of their organizational form, increased total VKM substantially (Figure 2). More VKT means more externalities, more intense infrastructure usage, and a less SM friendly environment. Reasons for this increase are, besides empty pick-up rides, substantial mode shifts from aPT and SM to AVs. If these additional VKM and mode shifts are accepted however, AVs have the potential to reduce total TT. Even without sophisticated pricing, vehicle relocation, etc., here, CHF 185'000.per day in reduced travel time cost could be achieved with aTaxis.

Focusing on the accompanying measures, the results did reveal the expected effects; price reduction of aPT and price increase in aMIT each leading to a decrease in total TT, while a reduced travel time burden in aMIT leads to an increase in TT. These effects however, could only be observed in a statistically non-significant range (Table 2).

In terms of policy recommendations, these results suggest to be careful with new AV based services. Policy makers are well advised to be critical about promises of such new services and to evaluate in detail how they fit into their particular transport system. While having the potential to reduce total TT and costs (as for example also shown by Merlin (36) for Ann Arbor), they likely increase traffic. This increases the risk for traffic jams and additional waiting times for customers and other traffic participants. A real life example for this is what happened with Uber in Manhattan (35). In this sense, the results also suggest policy makers and society to prepare for an "it will get worse before it gets better".

Small-scale experiments with AVs and the development of new services are to be encouraged as long as it does not cause too much additional traffic and does not disturb the existing system. When the day for large-scale introduction comes, policy makers should be aware however, that such a system would likely represent a very attractive competitor for existing PT solutions and SM.

Until this day comes however, policy makers are suggested to use the benefits of automation for the improvement of the existing system - a finding also supported by other recent studies (37; 38 ).

To conclude, it might not be as clear that services based on shared AVs will actually improve the overall performance of the system as often suggested. The existing system has grown and evolved during the past century. It is about 100 years, since affordable private cars came on the market, and thus the last major "game changer" in transport was introduced. Since then the system has been improved and a good balance between externalities, affordability and accessibility has been found which has supported the economic growth experienced in the decades since. If empty rides of private autonomous cars can be prevented or at least kept within reasonable limits, the results of this study suggest that the existing balance between mass transit and private transport is very suited to serve the current society and its spatial distribution. New services might lead to new spatial distributions leading to new requirements, which they will be more suitable to serve, but until then, one needs to be careful with what is to lose, when thinking about what could be won. 


\section{ACKNOWLEDGEMENT}

2 The authors would like to thank the four anonymous reviewers for their valuable inputs which 3 helped to improve the paper.

4 This research is funded by the Swiss National Science Foundation through project number 5 200021_159234, Autonomous Cars. 


\section{REFERENCES}

1. SAE International (2014) Taxonomy and Definitions for Terms Related to On-Road Motor Vehicle Automated Driving Systems, Warrendale, PA, January 2014, http:// standards. sae.org/j3016_201401\%

2. Bösch, P., F. Becker, H. Becker and K. Axhausen (2017) Cost-based analysis of autonomous mobility services, Working paper, 1225, Institute for Transport Planning and Systems (IVT), ETH Zurich, Zurich.

3. Fagnant, D. J. and K. M. Kockelman (2014) Preparing a Nation for Autonomous Vehicles: Opportunities, Barriers and Policy Recommendations for Capitalizing on Self-Driven Vehicles, paper presented at the 93rd Annual Meeting of the Transportation Research Board, Washington DC, January 2014.

4. Lutin, J. M., A. L. Kornhauser and E. Lerner-Lam (2013) The Revolutionary Development of Self-Driving Vehicles and Implications for the Transportation Engineering Profession, ITE Journal, 83 (7) 28-32.

5. Burns, L. D. (2013) Sustainable mobility: A vision of our transport future, Nature, 497, 181-182.

6. Burns, L. D., W. Jordan and B. Scarborough (2013) Transforming personal mobility, Technical Report, The Earth Institute, Columbia University.

7. Fagnant, D. J. and K. M. Kockelman (2014) The travel and environmental implications of shared autonomous vehicles, using agent-based model scenarios, Transportation Research Part C: Emerging Technologies, 40, 1-13.

8. Spieser, K., K. Treleaven, R. Zhang, E. Frazzoli, D. Morton and M. Pavone (2014) Toward a Systematic Approach to the Design and Evaluation of Automated Mobility-on-Demand Systems: A Case Study in Singapore, in G. Meyer and S. Beiker (eds.) Road Vehicle Automation, 229-245, Springer.

9. International Transport Forum (2015) Urban mobility system upgrade: How shared selfdriving cars could change city traffic, Technical Report, OECD, Paris.

10. Bösch, P. M., F. Ciari and K. W. Axhausen (2016) Required autonomous vehicle fleet sizes to serve different levels of demand, Transportation Research Record, 2542, 111-119.

11. Zachariah, J., J. Gao, A. Kornhauser and T. Mufti (2014) Uncongested Mobility for All: A Proposal for an Area Wide Autonomous Taxi System in New Jersey, paper presented at the 93rd Annual Meeting of the Transportation Research Board, Washington, January 2014.

12. Chen, D. T., K. M. Kockelman and J. P. Hanna (2015) Implications of a Shared, Autonomous, Electric Vehicle (SAEV) Fleet, paper presented at the 14th International Conference on Travel Behavior Research, Windsor, July 2015.

13. Zhang, R., K. Spieser, E. Frazzoli and M. Pavone (2015) Models, Algorithms, and Evaluation for Autonomous Mobility-On-Demand Systems, paper presented at the American Control Conference (ACC), Chicago, July 2015. 
14. Bischoff, J. and M. Maciejewski (2016) Autonomous taxicabs in Berlin - a spatiotemporal analysis of service performance, paper presented at the International Scientific Conference on Mobility and Transport Transforming Urban Mobility, mobil.TUM, Munich, June 2016.

15. May, A. D., S. P. Shepherd and P. M. Timms (2000) Optimal transport strategies for European cities, Transportation, 27 (3) 285-315.

16. May, A. D., S. P. Shepherd, G. Emberger, A. Ash, X. Zhang and N. Paulley (2005) Optimal Land Use - Transport Strategies - Methodology and Application to European Cities, Transportation Research Record: Journal of the Transportation Research Board, 1924, 129-138.

17. Zhang, X., N. Paulley, M. Hudson and G. Rhys-Tyler (2006) A method for the design of optimal transport strategies, Transport Policy, 13 (4) 329 - 338.

18. Kockelman, K., S. Boyles, P. Avery, C. Claudel, L. Loftus-Otway, D. Fagnant, P. Bansal, M. W. Levin, Y. Zhao, J. Liu, L. Clements, W. Wagner, D. Stewart, G. Sharon, M. Albert, P. Stone, J. Hanna, R. Patel, F. Hagen, T. Choudhary, T. Li, A. Nichols, K. Sharma and M. Simoni (2016) Bringing Smart Transport to Texans: Ensuring the Benefits of a Connected and Autonomous Transport System in Texas - Final Report, Report, 0-6838-2, Center for Transportation Research, The University of Texas at Austin, Austin, Texas, August 2016.

19. Horni, A., K. Nagel and K. W. Axhausen (eds.) (2016) The Multi-Agent Transport Simulation MATSim, Ubiquity, London.

20. Laesser, C. and S. Reinhold (2013) Finanzierung des OeV in der Schweiz: Was zahlt der Nutzer, was die Allgemeinheit?, Report, Schriftenreihe SBB Lab, St. Gallen.

21. VSS (2009) Kosten-Nutzen-Analysen (KNA) bei Massnahmen im Strassenverkehr: Zeitkosten im Personenverkehr, Norm, SN 641 822a, Swiss Association of Road and Transport Professionals (VSS), Zurich.

22. Schmid, B., S. Schmutz and K. W. Axhausen (2016) Explaining mode choice, taste heterogeneity and cost sensitivity in a post-car world, paper presented at the 95th Annual Meeting of the Transportation Research Board, Washington, D.C., January 2016.

23. Zuger Kantonalbank (2016) Der Kanton Zug in Zahlen - Ausgabe 2016, Report, Zuger Kantonalbank and Fachstelle für Statistik des Kantons Zug, Zug.

24. Rieser, M., K. Nagel and A. Horni (2016) Qsim, in A. Horni, K. Nagel and K. W. Axhausen (eds.) The Multi-Agent Transport Simulation MATSim, 77-80, Ubiquity Press, London.

25. Hörl, S. (2017) Agent-based simulation of autonomous taxi services with dynamic demand responses, paper presented at the 6th International Workshop on Agent-based Mobility, Traffic and Transportation Models, Methodologies and Applications (ABMTrans 2017), Madeira, May 2017.

26. Schuler, M., P. Dessemontet and D. Joye (2005) Raumgliederung der Schweiz, Technical Report, Swiss Federal Statistical Office (BFS), Neuenburg.

27. Zugerland Verkehrsbetriebe (2017) Startseite, Webpage (last accessed 01.08.2017), http: Tww. zvb.ch/en/home/. 
28. Bösch, P. M. and F. Ciari (2017) MacroSim - A macroscopic Mobsim for MATSim, Procedia Computer Science, 109, 861 - 868.

29. Tagesanzeiger (2017) SBB testen selbstfahrende Busse, Online article (last accessed 01.08.2017), March 2017, http://ww.tagesanzeiger.ch/wirtschaft/ unternehmen-und-konjunktur/sBB-testen-selbstfahrende-Busse/ story/29231859.

30. Bundesrat (2017) Bundesrat vertieft Mobility Pricing mit kantonaler Wirkungsanalyse, Online press release (last accessed 14.07.2017), July 2017, https://www.admin.ch/ gov/de/start/dokumentation/medienmitteilungen.ms-id-67431. htmi:

31. Bösch, P., K. Müller and F. Ciari (2016) The IVT 2015 baseline scenario, paper presented at the 16th Swiss Transport Research Conference, Ascona, May 2016.

32. Menzi, R. (2000) Die Landschaften der Schweiz - Landschaftstypologie Schweiz, Manual, Bundesamt für Raumentwicklung (ARE), Bundesamt für Umwelt (BAFU), Bundesamt für Statsitik (BFS), Bern.

33. Perret, C., J.-L. Muralti, C. Siegenthaler, C. Seewer, M. Kowald, A. Corpataux and A. Danalet (2017) Verkehrsverhalten der Bevölkerung - Ergebnisse des Mikrozensus Mobilität und Verkehr 2015, Technical report, Bundesamt für Statistik (BFS) and Bundesamt für Raumentwicklung (ARE), Neuchatel and Bern.

34. Bundesamt für Statistik (BFS), Bundesamt für Raumentwicklung (ARE) (2017) Verkehrsverhalten der Bevölkerung, Kenngrössen 2015 - Kanton Zug, Online data (last accessed 01.08.2017), https://www.zg.ch/behoerden/baudirektion/ statistikfachstelie/themen/li-mobilitaet-und-verkehry verkehr-1/downloads/Kenngroessen-MZ-2015-A2_ZG.xis/download:

35. Miller, S. (2015) Uber's own numbers show it's making traffic worse, Online article (last accessed 20.04.2016), http://www.streetsblog.org/2015/07/22/: ubers-own-data-reveals-it-slows-manhattan-traffic-9-percent/:

36. Merlin, L. (2017) Comparing automated shared taxis and conventional bus transit for a small city, Journal of Public Transportation, 20 (2) 19-39.

37. Meyer, J., H. Becker, P. M. Bösch and K. W. Axhausen (2017) Autonomous vehicles: The next jump in accessibilities?, Research in Transportation Economics, 62, 80-91.

38. Winkler, T. (2017) Selbstfahrende Fahrzeuge auf der ersten und letzten Meile des ÖVs, Master thesis, ETH Zurich, Zurich. 